\title{
Prevenir la amnesia colectiva: El acceso público a los archivos de televisión
}

\author{
Paloma HIDALGO GOYANES \\ pahidalg@ucm.es \\ Facultad de Ciencias de la Información. Universidad Complutense de Madrid. Unidad de \\ Análisis Documental. Archivo PP II de TVE
}

Recibido: 19/03/2013

Aceptado: 29/05/2013

\section{RESUMEN}

Los documentos que conservan los archivos audiovisuales de televisión son importantes para el trabajo de los investigadores y para el sector académico y educativo en general, pero no es habitual que los ciudadanos puedan acceder a ellos. Se analiza la situación actual al respecto en España, se apuntan los motivos que impiden el acceso a algunos de estos archivos, la ausencia de normativa legal y las posibles vías para lograr esa accesibilidad. Se compara con la situación al respecto en algunos países de nuestro entorno.

Palabras clave: Archivos audiovisuales, archivos de televisión, investigadores, accesibilidad, legislación.

\section{Preventing collective amnesia: Public access to television archives}

\begin{abstract}
The documents that preserve the audiovisual archives of television they are important for the researchers and for the academic and educational sector in general, but it isn't habitual that the citizens could accede to them. The situation is analyzed in the matter in Spain, there sign the motives that prevent the access some of these archives, the absence of legal regulation and the possible solutions to achieve this accessibility. It is compared with the situation in some countries of our environment.
\end{abstract}

Key words: audiovisual archives, television archives, researchers, accessibility, legislation. 


\section{INTRODUCCIÓN}

El objetivo y la razón de ser de los archivos han sido desde su inicio y a lo largo del tiempo recopilar, organizar y conservar la documentación generada por las instituciones, organismos, empresas o particulares de los que dependían. Posteriormente, la difusión del contenido de los documentos que componían su fondo fue cobrando importancia por voluntad de los profesionales que trabajaban en ellos y por parte de los usuarios en general, que comenzaron a solicitar esta información para el estudio y la investigación o como parte de sus derechos como ciudadanos, en particular cuando se trata de los documentos conservados en los archivos de titularidad pública.

En la Edad Contemporánea, la escritura dejaba de ser el vehículo de comunicación exclusivo; los avances tecnológicos permitieron que la información pudiera plasmarse de otras maneras dando origen a otro tipo de documentos (fotografías, películas, programas de radio y de televisión, etc.) y de manera consecuente con otra clase de archivos (fototecas, filmotecas, archivos de radio, archivos de televisión, etc.).

En este artículo, presentado con algunas variaciones como comunicación, se analizan los archivos audiovisuales de televisión como instrumentos útiles para el trabajo de los investigadores y para el sector académico y educativo en general, sin olvidar otros usuarios y usos potenciales. Igualmente trataremos de llamar la atención sobre los motivos que impiden aún el acceso a algunos de estos archivos y las posibles vías que permitirían su accesibilidad. Se examina básicamente la situación actual en España, aunque en ocasiones se hayan tomado como referencia comparativa países cercanos a nuestro entorno y legislaciones internacionales supranacionales existentes al respecto.

Debe quedar claro desde un primer momento que las reivindicaciones que se plantean al respecto de la accesibilidad de los archivos audiovisuales de televisión, tienen que ver con el acceso a través de ellos a una parte de nuestro patrimonio cultural y social; no se reivindica el acceso a estos documentos de manera libre y gratuita como bienes de consumo y por supuesto, tampoco se cuestiona el derecho de las empresas de televisión a explotar comercialmente sus archivos.

Actualmente, en casi todos los países existen archivos, bibliotecas y hemerotecas públicas, pero ¿por qué no existen archivos de radio y televisión, archivos audiovisuales públicos?

\section{LOS ARCHIVOS AUDIOVISUALES}

La "Sociedad de la Información", la sociedad del siglo XXI, ha descubierto hace tiempo la existencia de otro tipo de archivos, entre ellos, "los archivos audiovisuales", muchos de ellos vinculados a la producción cinematográfica y/ o a los medios de comunicación; los documentos que estos archivos gestionan y preservan son el reflejo y testimonio de los últimos cien años de la existencia de la humanidad. 
A finales de la década de los años veinte del pasado siglo, comenzaban las primeras emisiones regulares de televisión (en los inicios $\mathrm{BBC}, \mathrm{CBS}, \mathrm{NBC} . .$. ). La proliferación de cadenas de televisión y la implantación de este nuevo medio de comunicación en la década de los cincuenta, favoreció la creación de los archivos audiovisuales de estos medios de comunicación que pronto acumularon gran cantidad de documentos.

Como ya hemos comentado, desde su creación los archivos audiovisuales guardan informaciones y testimonios reales sobre los acontecimientos importantes o cotidianos de nuestra historia contemporánea; documentos que dan fe de acontecimientos y costumbres, de la existencia humana, desde finales del siglo XIX hasta ahora, y que no sólo certifican los hechos, sino que tienen el poder de hacer que los revivamos en cierto modo, ya que estos documentos, en los que sus protagonistas recobran voz y movimiento cuando los consultamos, son un espejo que nos devuelve nuestra propia imagen, la de nuestra ciudad, nuestro país y que evoca nuestros recuerdos sobre acontecimientos concretos al verlos reflejados en imagen, conformando un imaginario colectivo que sirve de referencia para la reconstrucción de nuestra historia y de la denominada por la UNESCO "Memoria del Mundo".

Ahora, cuando ya es posible recuperar las imágenes de personas o sucesos importantes al cumplirse el aniversario de los mismos, aunque hayan ocurrido hace ya más de 50 años, es curioso constatar como todos somos capaces de evocar las situaciones vividas al ver las imágenes de estos acontecimientos, comprobando que en realidad es cierto que existe "una memoria colectiva". Para completar esta reflexión bastaría como ejemplo enumerar algunos acontecimientos de los que durante el pasado año 2012 se ha celebrado aniversario y comprobar que sólo hemos podido recordar algunos de ellos en las emisiones de televisión, porque los documentos audiovisuales grabados al respecto en su día, se conservan en los archivos de televisión. Así ha sido posible recuperar y utilizar imágenes de acontecimientos como el inicio de la guerra de Bosnia (1992) o de las primeras grabaciones y actuaciones de The Beatles (1962), pero no hay ningún testimonio televisivo de la promulgación de la Constitución española por las Cortes de Cádiz en 1812 ni del hundimiento del Titanic (1912).

La Conferencia General de la UNESCO celebrada en Belgrado en 1980, en su $21^{\text {a }}$ reunión, propone la "Recomendación sobre la salvaguardia y la conservación de las imágenes en movimiento", después de concluir que "las imágenes en movimiento son una expresión de la personalidad cultural de los pueblos y que, debido a su valor educativo, cultural, artístico, científico e histórico, forman parte integrante del patrimonio cultural de una nación".

\footnotetext{
${ }^{1}$ Recomendaciones de la UNESCO para la Salvaguardia y Conservación de las Imágenes en movimiento http://unesdoc.unesco.org/images/0011/001140/114029s.pdf
} 
Se considera además que las imágenes en movimiento son nuevas formas de expresión, particularmente características de la sociedad actual y que por tanto, en ellas se refleja una parte importante de la cultura contemporánea y puesto que registran los acontecimientos diarios, "aportan testimonios importantes y a menudo únicos, de la historia, el modo de vida y la cultura de los pueblos así como de la evolución del universo". La recomendación efectuada por la UNESCO, observa también que este tipo de imágenes habría de desempeñar cada vez un papel más importante como medio para la comunicación y comprensión entre los pueblos.

Se reparaba ya en este momento en el hecho de que las características físicas del soporte donde se grababan estas imágenes y los métodos empleados para su fijación en los mismos les conferían una cierta inestabilidad y vulnerabilidad que ponía en peligro la permanencia y conservación de este tipo de documentos y por tanto el peligro de conservación de este patrimonio. En consecuencia, se recomendaba e invitaba a los Estados tomar las medidas adecuadas para "garantizar la salvaguardia y conservación de las imágenes en movimiento", teniendo en cuenta las obligaciones que impone el derecho internacional, así como la posición legítima de los titulares de derechos de autor y demás derechohabientes. A todos los efectos, UNESCO incluye en esta Recomendación "las producciones televisivas realizadas por o para los organismos de radiodifusión".

La importancia del patrimonio audiovisual para la historia y la identidad cultural y social de los pueblos es indiscutible, y la recomendación de la UNESCO supuso un avance muy importante, pero todavía hoy son muy pocos los países que tienen una legislación al respecto de los archivos audiovisuales. UNESCO ha declarado el día 27 de octubre como "Día Mundial de la Herencia Audiovisual" (celebrado por primera vez en el año 2008). Sin embargo, hoy en día el desconocimiento de la existencia de muchos de estos archivos audiovisuales y la falta de políticas públicas de conservación, preservación y acceso a los documentos que estos archivos contienen sigue siendo habitual y también lo es en España.

El Programa "Memoria del Mundo"2 promovido también por la UNESCO, creado en el año 1992, y que por tanto celebra este año su 20 aniversario, rubrica la importancia de estos archivos ya que "determina el patrimonio documental de importancia internacional, regional y nacional; lo inscribe en un registro, y otorga un logotipo para identificarlo. Facilita asimismo su preservación y el acceso sin discriminación. Además, organiza campañas para sensibilizar sobre el patrimonio documental, alertar a los poderes públicos, a los ciudadanos y a los sectores empresarial y comercial de las necesidades de preservación y de recaudar fondos para salvar estos archivos".

\footnotetext{
${ }^{2} \mathrm{http} / /$ www.unesco.org/new/es/communication-and-information/flagship-project-activities/ memoryof-the-world/
} 


\section{MARCO LEGISLATIVO}

El planteamiento que debiera hacerse al respecto del patrimonio audiovisual, incluyendo los archivos de televisión, es claro y conciso: al igual que el patrimonio cultural artístico o bibliográfico necesita la actuación de las administraciones públicas o de instituciones y fundaciones privadas para la restauración, conservación y preservación del mismo, el objetivo debe ser que esos mismos recursos públicos y privados procuren la salvaguarda y el conocimiento de los archivos audiovisuales para los ciudadanos. Las recomendaciones encaminadas a lograr este fin son un avance positivo, pero no se traducen en nada si no van acompañadas de una auténtica voluntad política y cívica por mantener este patrimonio, lo que incluye lógicamente inversiones económicas y una reglamentación o normativa legal precisa al respecto.

En este epígrafe, intentaremos hacer un breve repaso al marco legal existente en España al respecto de los archivos audiovisuales y la consideración que nuestras leyes y normas otorgan a los mismos. Analizaremos las referencias concretas que la legislación actual vigente hace a los archivos audiovisuales de televisión.

La ley del Patrimonio Histórico, publicada en el año $1985^{3}$, lo define en su preámbulo como "principal testigo de la contribución histórica de los españoles a la civilización universal y de su capacidad creativa contemporánea". En ella se consagra una nueva definición del concepto de patrimonio histórico, que se amplía también al "Patrimonio Documental y Bibliográfico". Su protección queda también expresamente indicada en el artículo 46 de La Constitución Española.

En la ley de Patrimonio se hace referencia concreta a los documentos sonoros y de imagen en su artículo 49.1 (incluido en el Título VII, capítulo I) y además el apartado 2 del mismo artículo 49 establece claramente que "forman parte del Patrimonio Documental los documentos de cualquier época generados, conservados o reunidos en el ejercicio de su función por cualquier organismo o entidad de carácter público, por las personas jurídicas en cuyo capital participe mayoritariamente el Estado u otras entidades públicas y por las personas privadas, físicas o jurídicas, gestoras de servicios públicos en lo relacionado con la gestión de dichos servicios." Del carácter patrimonial de estos archivos se deriva el deber de conservar las imágenes generadas, tal como se ordena en el artículo 52.1: "Todos los poseedores de bienes del Patrimonio Documental y Bibliográfico están obligados a conservarlos, protegerlos, destinarlos a un uso que no impida su conservación y mantenerlos en lugares adecuados." Es tal la protección que se otorga en la ley que el incumplimiento del deber de conservación "podrá ser causa de interés social para la expropiación forzosa de los bienes afectados".

${ }^{3}$ Ley 13/1985, de 25 de junio, del Patrimonio Histórico Español. BOE 155, sábado 29 junio 1985, págs. 20342-20352 
- La ley General de Comunicación Audiovisual de 2010 ${ }^{4}$, hace referencia en su preámbulo al peso y trascendencia de la industria audiovisual en la economía y a que "los contenidos audiovisuales y su demanda forman parte de la vida cotidiana del ciudadano actual". Sin embargo, sólo la disposición adicional sexta menciona los archivos audiovisuales desde un punto de vista patrimonial al indicar que "los operadores de comunicación audiovisual, estarán obligados a preservar y a conservar el archivo de imágenes en movimiento y audio".

- En el caso concreto de TVE, la televisión estatal de titularidad pública en España, la Ley 17/2006, de 5 de junio, de la radio y la televisión de titularidad estatal ${ }^{5}$, dice en el Artículo 3. Encomienda del servicio público de radio y televisión. 2. "En el ejercicio de su función de servicio público, la Corporación RTVE deberá, entre otras cosas, velar por la conservación de los archivos históricos audiovisuales".

- En este mismo sentido, el Mandato-Marco de la Corporación de RTVE ${ }^{6}$, capítulo VI, artículo 52, relativo al "Patrimonio Audiovisual", indica:

En virtud del artículo 3.2.o), de la Ley 17/2007, que incluye en la función de servicio público la conservación de los archivos históricos audiovisuales, la Corporación RTVE tiene la obligación, en el período de vigencia del presente Mandato-marco, de "digitalizar, conservar y preservar, en condiciones óptimas para su uso y consulta, el archivo histórico heredado de RTVE. Las cantidades a invertir anualmente en este proceso serán determinadas en cada Contrato-programa. El patrimonio audiovisual sujeto a este articulado no podrá ser abandonado, ni enajenado”.

- En las Autonomías que componen el Estado Español, existen Consejos Audiovisuales y se han elaborado normativas y legislaciones al respecto de la conservación del patrimonio audiovisual por parte de las televisiones autonómicas. Su marco legal al respecto del patrimonio histórico, cultural y documental incluye también los documentos audiovisuales en la mayoría de los casos.

- La Ley de las Televisiones Privadas, Ley Orgánica 10/1988, de 3 de mayo, en su artículo 14.6 obliga a las empresas audiovisuales a guardar durante seis meses «a contar desde la fecha de su primera emisión» una copia de las emisiones en prevención de cualquier reclamación, así como a registrar los datos de los programas.

\footnotetext{
${ }^{4}$ Ley 7/2010, de 31 de marzo, General de la Comunicación Audiovisual.

${ }^{5}$ Ley 17/2006, de 5 de junio de la radio y televisión de titularidad estatal. BOE 134, martes 6 de junio 2006, págs. 21207-21218.

${ }^{6}$ Aprobación por los Plenos del Congreso de los Diputados y del Senado del mandato-marco a la Corporación RTVE previsto en el artículo 4 de la Ley 17/2006, de 5 de junio, de la radio y la televisión de titularidad estatal. BOE 18 diciembre de 2007, $\mathrm{n}^{\circ} 470$
} 
- La reciente Ley de Depósito Legal 23/2011 ${ }^{7}$, de 29 de julio de 2011, que sustituye a las normativas vigentes desde los años 1971 y 1973, se refiere en el preámbulo al patrimonio bibliográfico, sonoro, visual, audiovisual y digital de las culturas de España como uno de los más ricos del mundo indicando que debe ser preservado en beneficio de las generaciones presentes y futuras. En las Disposiciones Generales, Capítulo I, Artículo 3, Definiciones, se especifica que la ley entiende por documento "toda información cualquiera que sea su soporte material o electrónico así como su forma de expresión gráfica, sonora o en imagen utilizada".

Sin embargo, la custodia del patrimonio audiovisual a diferencia de lo que sucede en otros países, sigue en manos de los radiodifusores, en este caso las cadenas de televisión, por lo que el sistema presenta algunos problemas, derivados esencialmente de la aplicación de criterios particulares de carácter empresarial, económico, editorial, y de la posibilidad y voluntad de las direcciones de las respectivas cadenas de televisión para facilitar el acceso de los ciudadanos a la información contenida en esos documentos, etc.

La diferencia de situaciones en Europa deriva en unos casos de la falta de leyes sobre depósito legal para las obras audiovisuales y en otras del hecho de que estas leyes designen en unos casos a la Administración Pública, en el nivel correspondiente y en otros a los productores, difusores y distribuidores como responsables de la gestión y conservación del patrimonio audiovisual lo que ha motivado la inexistencia de un organismo o institución público, al margen de intereses comerciales o patrimoniales de otra índole, que aglutine, preserve, gestione y conserve todo este patrimonio cultural.

En algunos países de Europa existe una ley de depósito legal para los documentos audiovisuales que "incluye las emisiones y producciones de televisión", por lo que existe un marco jurídico que regula la recopilación, gestión y conservación de los mismos como responsabilidad de organismos o instituciones públicas creadas a tales efectos, al margen de la responsabilidad adjudicada en cada caso a los organismos productores y difusores de televisión. Lógicamente, también queda reglamentado el acceso público a estos archivos. Cabe citar entre ellos: Francia (INA), Noruega (Biblioteca Nacional), Suecia (Departamento de material audiovisual de la antiguo SLBA) o Suiza (Asociación Memoriav) ${ }^{8}$. 86727

${ }^{7}$ Ley 23/2011, de 29 de julio de Depósito Legal, BOE 30 de julio de 2011, no 182, págs. 86716-

${ }^{8}$ Francia http://www.ina.fr/, Noruega http://www.nb.no/, Suecia http://www.kb.se/hjalp/english/, Suiza http://www.memoriav.ch/ 


\section{LOS ARCHIVOS AUDIOVISUALES DE LAS TELEVISIONES}

Los medios de comunicación en su conjunto contribuyen a la representación de la realidad ya que captan, informan y en ocasiones interpretan los acontecimientos. La televisión supuso la llegada de lo audiovisual a la vida cotidiana de los ciudadanos, de los telespectadores, de manera que las noticias importantes, se podían mezclar con programas sobre vivencias particulares y cotidianas, entretenimiento, etc. La proliferación de cadenas de televisión y la supremacía (en cuanto a presencia en la sociedad) de este nuevo medio de comunicación en la década de los cincuenta del siglo pasado, hizo surgir paulatinamente la idea de que "las imágenes que se emitían eran el reflejo de la vida cotidiana de cada país, y que podrían conformar su memoria histórica".

Los archivos audiovisuales de las cadenas de televisión nacen en principio por y para solventar las necesidades que plantean la producción y emisión diarias de estos medios de comunicación; tienen desde su origen y hasta la actualidad un carácter evidente y eminentemente empresarial, que hace que su objetivo básico sea facilitar el trabajo del medio al que sirven, es decir, su participación como factor decisivo en la actividad diaria de la cadena con el consiguiente ahorro de tiempo y dinero, convirtiéndose además en un activo patrimonial básico para estas empresas y también en una fuente de negocio.

No son por tanto en sí mismos instituciones u organismos garantes de la preservación de la memoria colectiva, a diferencia de los archivos audiovisuales de carácter público que detentan el depósito legal de este patrimonio.

La actividad diaria de los servicios de documentación de las emisoras de televisión, debe tener, en principio, una triple finalidad relacionada directamente con la consecución de este objetivo de manera que permita asegurar la conservación de los documentos y la localización y recuperación de toda la información contenida en ellos. Por eso se diseñan y ponen en práctica los flujos de trabajo necesarios para:

a) Recopilar, seleccionar, almacenar y gestionar la documentación generada, utilizada o emitida por la empresa de televisión a la que pertenecen.

b) Facilitar y proporcionar a los usuarios la información documental que necesiten.

c) Garantizar la conservación y preservación del fondo documental de la empresa.

Las características de la documentación audiovisual generada y gestionada en las televisiones, entre las cuales cabría citar su origen diverso, el enorme volumen, la heterogeneidad (de soportes y contenidos), su interdisciplinaridad especialmente en las televisiones de carácter generalista), la dispersión y una cierta obsolescencia (aunque perdida su validez como referente de la actualidad informativa cobra un importante valor histórico, sociológico y cultural), confieren su valor e importancia a los servicios de documentación audiovisual de estos medios de comunicación. Desde la década de los ochenta, las televisiones, especialmente las de titularidad pública, 
fueron conscientes del valor patrimonial de este acervo audiovisual, que habían generado como consecuencia de su actividad empresarial.

Sin embargo en un primer momento, los documentos audiovisuales de televisión tampoco fueron tenidos en cuenta por el sector académico como fuente de estudio científico, quizá por considerarlo un medio esencialmente de entretenimiento, nada riguroso a la hora de representar la realidad e incluso tendencioso en ocasiones. Según estudios realizados por el Centro de Documentación del Conseil Superieur de l'Audiovisuel (CSA) de Bélgica', se han producido en los últimos años algunos cambios para que los investigadores soliciten esta documentación:

1. La posibilidad de acceder progresivamente a las fuentes documentales audiovisuales.

2. La evidencia creciente del papel que ha jugado y juega la televisión en el conocimiento del mundo contemporáneo.

3. El aprendizaje y desarrollo de la capacidad de los investigadores para leer y analizar el material audiovisual, que posee un lenguaje propio

Hay tantos accesos potenciales al fondo documental de un archivo de televisión como investigadores. La información suele ser la materia prima esencial de investigadores en ciencias humanas: los historiadores, por ejemplo, intentarán comprobar el modo en que la televisión cubrió un acontecimiento concreto como la guerra de Vietnam; los sociólogos realizarán un estudio para evaluar el impacto de televisión sobre la familia u otros sectores sociales (por ejemplo, para examinar la cobertura y el impacto de los acontecimientos del 11 de septiembre de 2001 en los habitantes de Nueva York); los analistas políticos estarán interesados en las relaciones internacionales, acontecimientos políticos y las diversas evaluaciones que éstos han tenido en las televisiones, según las épocas; lingüistas, especialistas en comunicación audiovisual, etc. obtienen una valiosa información para sus estudios e investigaciones en los archivos audiovisuales de las televisiones.

En la mayoría de los países de nuestro entorno, son las propias empresas y organismos de televisión quienes han creado los servicios de documentación audiovisual más importantes, tal es el caso de BBC (Reino Unido), RAI (Italia), ZDF (Alemania), ORF (Austria), RTP (Portugal), etc. y quienes se encargan de gestionarlos y conservarlos.

En España, tanto las cadenas de televisión de titularidad pública (la estatal TVE y las televisiones autonómicas), como las cadenas privadas importantes (Antena 3, Tele Cinco, La Sexta, etc.) cuentan con servicios de documentación en los que almacenan, gestionan y conservan los documentos audiovisuales, parte esencial del patrimonio

\footnotetext{
${ }^{9}$ http://www.csa.be/
} 
económico empresarial. Sin embargo no existe un marco legal apropiado para promover, asegurar y facilitar la accesibilidad a estos fondos documentales, y a las televisiones en general, también les queda por llevar a cabo una fase importante de su trabajo: poner en valor sus archivos y darlos a conocer. Los usuarios potenciales deben saber que el archivo existe, que es un elemento valioso y que no es sólo parte de la trastienda de las cadenas de televisión.

\section{EL ACCESO A LOS FONDOS: ASIGNATURA PENDIENTE DE LOS ARCHIVOS AUDIOVISUALES DE TELEVISIÓN}

Conservar los documentos no debe ser por sí mismo el objetivo para los profesionales de los Archivos. Se conservan con el claro propósito de que puedan ser reutilizados, de que la información que contienen se transmita a través del tiempo y el espacio; al tratarse de un medio de comunicación, la recuperación y difusión de la información que contienen estos documentos debe ser un objetivo básico. En un entorno digital el papel de los documentalistas audiovisuales de televisión como "gestores de contenidos" es aún más necesario.

Como acertadamente señala Edmonson "la conservación y el acceso son dos caras de la misma moneda... Aunque es necesaria para garantizar la accesibilidad permanente, la conservación no es un fin en sí misma. A falta del objetivo de acceso, carece de sentido" 10 .

La accesibilidad a los archivos, también a los de televisión, debe tener el respaldo de las políticas de las administraciones públicas y al igual que se promulgan leyes al respecto a la preservación de la documentación, deberían elaborarse normas reguladoras del acceso de los ciudadanos (restrictivo o no, según los casos) a la consulta de estos fondos documentales.

La Recomendación de Belgrado, en sus "Principios Generales", punto 6, dice que "se debería facilitar el más amplio acceso posible a las obras y fuentes de información que representan las imágenes en movimiento adquiridas, salvaguardadas y conservadas por instituciones públicas o privadas de carácter no lucrativo. La utilización de esas imágenes en movimiento no debería perjudicar los derechos legítimos ni los intereses de quienes intervienen en su producción y explotación, según lo estipulado en la Convención universal sobre derecho de autor, el Convenio de Berna, y en la legislación nacional". Además, en el punto 13 del mismo apartado, se invita a los Estados Miembros a estudiar la posibilidad de autorizar a los archivos reconocidos oficialmente, teniendo en cuenta todas las cuestiones de carácter jurídico pertinentes,

\footnotetext{
${ }^{10}$ Edmondson, R. y miembros de la AVAPIN: Una filosofía de los archivos audiovisuales. Programa General de Información y UNISIST. Paris, Organización de las Naciones Unidas para la Educación, la Ciencia y la Cultura, 2004, p. 22.
} 
a que el material depositado en ellos pueda reutilizarse con fines de investigación y enseñanza académica, sin que se menoscabe con ello la explotación normal de las obras audiovisuales.

También uno de los tres objetivos básicos del Programa Memoria del Mundo es facilitar "el acceso universal al patrimonio documental", mediante actividades consistentes en promover la producción de copias digitalizadas y catálogos consultables en Internet y en publicar y distribuir libros, CD, DVD y otros productos de manera tan amplia y equitativa como sea posible, teniendo en cuenta los derechos restricciones legales y de otro tipo en materia de accesibilidad a los archivos.

El acceso a los documentos y especialmente el permiso de acceso de los ciudadanos a la información contenida en los documentos que custodian organismos, instituciones y/o empresas de titularidad pública, también las televisiones, es una de las situaciones frecuentes que deben solventar los profesionales que trabajan en ellos al atender a los usuarios que solicitan estas consultas cada vez más frecuentemente y que llegan a plantearlas en ocasiones como un derecho ciudadano más. Habría que matizar y recordar quizá que el derecho de acceso a la documentación pública no es el derecho a recibir información, sino el derecho del ciudadano a informarse.

La doble perspectiva que me aporta la experiencia profesional como documentalista audiovisual de televisión y como docente e investigadora, hace que en esta reflexión, no se plantee ni discuta en modo alguno el derecho que tienen todos los organismos productores de televisión sobre sus archivos, sobre su reutilización y explotación comercial, lo que se plantea es si en todos los países, entre ellos España, se garantiza y protege igualmente este patrimonio desde un punto de vista no exclusivamente empresarial, sino desde la perspectiva de la pertenencia de estos documentos audiovisuales al patrimonio histórico y cultural de estos países y por tanto a crear mecanismos que posibiliten el acceso de los ciudadanos a estos archivos con las garantías legales suficientes. Se plantea la existencia o la creación en caso de que no existan, de normas e instrumentos legales que, en nuestra opinión, deberían tomar como referencia las recomendaciones y normas internacionales existentes al respecto, vigentes desde hace tiempo y que han dado resultados muy satisfactorios.

Los archivos de las televisiones privadas conservan también una importante documentación audiovisual y realizan esfuerzos y acciones importantes dirigidas a la preservación de estos fondos documentales, pero la legislación española no fija para ellos las mismas obligaciones que para los archivos de las cadenas de televisión públicas.

Según plantea R. Edmondson, el significado del término "acceso" puede ser más o menos amplio, según el uso que se haga de los fondos, servicios o conocimientos de un archivo audiovisual. Además, el acceso puede tener carácter "activo" (iniciado por la propia institución) o "reactivo" (iniciado por los usuarios de la institución).

En mi opinión cabría plantear al menos cuatro tipos de modalidad de acceso de los ciudadanos a los documentos de los archivos audiovisuales de las televisiones: 
a) El acceso para los investigadores

b) El acceso para los profesionales y empresas del sector audiovisual

c) El acceso para el sector académico (con fines educativos)

d) El acceso para usuarios y público en general a través de internet

Nos centraremos sobre todo en la primera de las modalidades, por ser la menos resuelta hoy en día en el Estado Español y quizá una de las más demandadas en un futuro próximo.

\subsection{El acceso para los investigadores}

La consulta de documentos audiovisuales como fuente de estudio y más concretamente aún, la de los documentos audiovisuales de televisión, sigue siendo poco frecuente en España, a no ser en el ámbito de las facultades de comunicación, por razones obvias. En algunos casos es resultado del desconocimiento (ya que no siempre se sabe de la existencia de estos archivos) y en otros, de los problemas que los investigadores encuentran para poder acceder a estos fondos documentales. ¿Por qué es relativamente fácil consultar bibliotecas o documentación textual sobre algún político o escritor famoso, por ejemplo, y no lo es tanto consultar entrevistas suyas en programas de televisión?

La mayoría de los investigadores que solicitan el permiso para acceder a consultar los archivos audiovisuales de las televisiones provienen, como ya hemos apuntado, del campo de la Comunicación (periodistas, publicistas, realizadores, guionistas, etc.); historiadores, sociólogos y politólogos, van aumentando su presencia. En el primero de los casos, la formación inicial de los investigadores suele permitirles la consulta y visionado de los documentos sin grandes problemas; en el resto, es necesaria una mínima formación y apoyo por parte de los profesionales del archivo, factor a tener en cuenta a la hora de decidir sobre la accesibilidad a los mismos. A este sector de la investigación se han unido en los últimos años algunos profesionales de la documentación, los denominados " researchers o freelance researchers", documentalistas especializados en la búsqueda de documentos en los archivos audiovisuales (entre ellos en los de las televisiones) y en la negociación de los derechos inherentes a este tipo de materiales, normalmente para reutilizarlos en nuevas producciones.

La posibilidad que los investigadores puedan acceder a consultar y trabajar con los fondos de los archivos de televisión, suele variar si son archivos de titularidad pública (INA) o de titularidad privada, dependiendo en este último caso, de la política de la empresa a la que pertenecen, de la disponibilidad de copias, de si el fondo documental está o no digitalizado, de las disposiciones en materia de derechos de autor y derechos contractuales y también, de la legislación vigente al respecto en cada país, (en el caso de que exista). 
- En España, el acceso a la consulta de los fondos audiovisuales de las televisiones, al menos de las televisiones de titularidad pública, queda reservado casi exclusivamente para los investigadores y/o profesores de universidad, con la acreditación pertinente y previo visto bueno de los responsables de la dirección de la empresa.

Durante el mes de julio del año en curso elaboré un breve cuestionario ${ }^{11}$ para conocer la situación actual al respecto de esta cuestión, la accesibilidad de investigadores y otros usuarios a los archivos audiovisuales de las televisiones, que distribuí a los responsables de los archivos y servicios de documentación audiovisual de algunas televisiones públicas autonómicas, las de mayor trayectoria: Canal Sur (Andalucía), ETB (País Vasco), TVG (Galicia), TV3 (Cataluña), TVV (Comunidad Valenciana) y Telemadrid (Comunidad de Madrid) que he analizado y comparado junto a las condiciones de accesibilidad en el archivo de TVE, para extraer los siguientes resultados:

a) En algunos de estos archivos se admiten y procesan consultas de usuarios externos, pero normalmente las relacionadas con la actividad comercial y/o institucional de la empresa (venta de imágenes, imágenes para instituciones públicas o asociaciones sin ánimo de lucro, etc.). Sólo en dos de las televisiones estas peticiones son atendidas por el Departamento de Documentación (Archivo), en el resto, atienden las consultas y peticiones los departamentos comerciales que tienen acceso a consultar las bases de datos documentales. No es habitual en ninguna de ellas atender consultas de particulares.

b) Prácticamente en todos los casos consultados, salvo en el de la TVV (Comunidad Valenciana) y en el de Telemadrid ${ }^{12}$, existe posibilidad de consulta del fondo documental para los investigadores, cumpliendo una serie de "características de perfil" (profesores universitarios, doctorandos, investigadores acreditados, etc.) y administrativas (respaldo de una institución académica y/o cultural, presentación resumida del proyecto de investigación, permiso del representante pertinente por parte de la Dirección de la cadena, etc.). La consulta siempre es "in situ" y bajo la supervisión del personal del Departamento de Documentación.

c) En ninguno de estos archivos los catálogos de los fondos audiovisuales son accesibles (online o manuales) para los investigadores.

\footnotetext{
${ }^{11} \mathrm{Mi}$ agradecimiento por su colaboración a $\mathrm{M}^{\mathrm{a}}$ Angeles Martin (Canal Sur), Jesús Andérez (ETB), Chus López (TVG), Alicia Conesa (TV3), Lola Alfonso (TVV), Blasi Naranjo (Telemadrid) y mi reconocimiento al resto de los profesionales que trabajan en los archivos de estas televisiones y a mis compañeros del archivo de TVE.

${ }^{12}$ En el caso de TVV, sólo se colabora en proyectos fin de carrera o tesis doctorales elaboradas en colaboración directa con la Corporación RTVV. Telemadrid aduce no disponer de infraestructura para responder a tales demandas.
} 
d) Según veremos en el apartado correspondiente, en la página web de estas televisiones hay presencia del archivo, pero en relación con documentos emitidos (nunca originales sin editar), seleccionados por la propia empresa, tanto de la emisión actual como del archivo histórico de la cadena; no hay acceso a todo el fondo documental por las razones de tipo legal que comentaremos en el apartado correspondiente.

e) Normalmente, todos los archivos suelen coincidir en establecer un perfil de consultante y unos requisitos para poder efectuar las consultas al archivo; generalmente también, no se permite la copia de imágenes para su reutilización. Los investigadores no pagan por los costes (recursos humanos y materiales puestos a su disposición) que se derivan de la búsqueda y recuperación de la información solicitada en las bases de datos y el visionado de los documentos pertinentes.

Precisamente la vocación de "servicio público" de estos archivos es en la mayoría de los casos contradictoria con la falta de recursos humanos y materiales para poder prestar este tipo de servicios en condiciones idóneas.

Los problemas legales son consustanciales a la reutilización de algunos de estos documentos, incluso para el propio medio de comunicación, por lo que resulta aún más complejo el acceso y reutilización de esta información por parte del público en general. No obstante hay fórmulas posibles, sobre todo en el ámbito que aquí se trata, el acceso de los investigadores a los archivos audiovisuales de televisión, sin que exista en esta actividad ánimo de lucro; en estas circunstancias, es fundamental que el archivo tenga información puntual sobre estos derechos.

Tradicionalmente, se considera que hay tres tipos de derechos básicamente que afectan de manera directa a la reutilización de las imágenes de archivo:

- Derechos de autor (morales y patrimoniales) y derechos conexos ${ }^{13}$

- Derechos contractuales

- Derechos de imagen ${ }^{14}$

Evidentemente, el hecho de facilitar el acceso a estos archivos supone que en ellos se ha efectuado una completa y correcta labor de inventariado, sistematización, y análisis documental de todos y cada uno de los documentos incluidos en el catálogo, su informatización en una base de datos y una correcta preservación de los documentos que componen esos fondos documentales, de manera que sea posible su consulta y

\footnotetext{
${ }^{13}$ En España la Ley de Propiedad Intelectual aprobada por Real decreto Legislativo 1/1996 de 12 de abril, regula los derechos de autor de las producciones audiovisuales. A través de esta norma, se implementó en España la Directiva 93/98/CEE.

${ }^{14}$ Estos aspectos quedan regulados por la Ley Orgánica 1/1998 de Protección al Honor, Intimidad personal y Familiar y propia Imagen, así como la Ley Orgánica de Protección al Menor 1/1996.
} 
visionado. Todo esto implica la existencia de un grado de conciencia elevado por parte de la dirección de la empresa o institución que posee la titularidad de ese acervo, sobre el valor social y cultural de los archivos audiovisuales.

No obstante, a diferencia de lo que sucede con otro tipo de archivos, no es habitual que en los archivos audiovisuales de televisión existan guías o catálogos de los fondos automatizados de libre consulta para los usuarios, por lo que son los documentalistas de estos medios de comunicación quienes se encargan de atender las solicitudes de información y atender la consulta y visionado de los investigadores.

Este es otro obstáculo a tener en cuenta en el acceso a los fondos documentales de los archivos de televisión que, podríamos decir, es un acceso "restringido", pero no por cuestiones de censura sino por cuestiones de carácter simplemente práctico y operativo, debido a que confluyen algunas de las siguientes circunstancias:

a) El investigador efectúa lo que en el entorno profesional se denomina "búsqueda delegada", ya que son los documentalistas de cada televisión quienes, como hemos dicho, efectúan la búsqueda y recuperación de la información demandada y orientan al usuario, una vez que conocen sus necesidades de información, sobre los documentos del archivo que podrían responder a su demanda y contener la información que se precisa.

b) Las bases de datos pueden contener también información de carácter empresarial que no debe distribuirse públicamente.

c) Los usuarios, no suelen estar familiarizados con la lectura de este tipo de documentos (los audiovisuales) y menos aún con su análisis documental. Es necesario el aprendizaje y desarrollo de una serie de competencias y técnicas, que al menos al principio requieren también de la instrucción y el apoyo de profesionales especializados.

d) Habitualmente, en ningún caso se proporciona a los investigadores copia de la documentación audiovisual con la que trabajan, precisamente por todos los derechos inherentes a este tipo de material.

e) Los archivos están ubicados en la sede de las propias empresas donde no existen normalmente salas de consulta destinadas a tal fin ni personal encargado exclusivamente de atender a quienes investigan estos fondos. Hay que hacerlo compatible con el trabajo y la actividad diaria de la unidad de documentación de esa televisión.

El acceso de investigadores a los archivos de televisión supone un coste económico y personal difícil de asumir, pero los medios de comunicación de titularidad pública, al tener encomendada la gestión y preservación de este patrimonio, entienden generalmente que esto implica también posibilitar el acceso y consulta a los mismos a algunas personas y en condiciones concretas, en la medida de lo posible.

La política de cada Estado al respecto del patrimonio cultural origina claras diferencias, puesto que la ausencia de normativas legales específicas al respecto del 
patrimonio cultural audiovisual, deja irremediablemente en manos de empresas e instituciones productoras y difusoras la voluntad de conservar o no estos archivos y de permitir o no el acceso de los investigadores a consultarlos.

En nuestro entorno, el caso de Francia es quizá el más paradigmático: la ley de 20 de junio de 1992 extendía la obligación del Depósito Legal a los programas de radio y televisión, misión confiada al Instituto Nacional de lo Audiovisual (INA). La ley de 1 de agosto de 2006, confiaba también a esta institución el depósito legal de los sitios web de los medios audiovisuales franceses.

L'Inatèque de Francia se crea en 1995, con el fin de asegurar la conservación del patrimonio audiovisual del país y la consulta de los programas de radio, televisión y sitios web; atiende a todas las personas que justifiquen un tema de investigación, esencialmente a los investigadores, estudiantes, profesores de todas las disciplinas, así como a los profesionales. El centro de consulta pública de la Inatèque está situado físicamente en la sede François Miterrand de la Biblioteca Nacional en Paris.

El fondo contiene documentos audiovisuales de televisión desde 1949, y cubre todos los géneros: informativos diarios, magazines, documentales, debates, entrevistas, series de ficción, telefilms, concursos, deportes, etc. pero se trata siempre de "programas emitidos". Diariamente se graban los programas de casi un centenar de cadenas de televisión francesas, nacionales e internacionales, cientos de miles de horas de emisión de televisión que después son identificadas, analizadas, descritas y conservadas. Los diferentes derechos inherentes a este tipo de material, son negociados por el INA con productores y difusores.

Un equipo de documentalistas y técnicos orienta y asiste a los investigadores en las búsquedas de información en las bases de datos, así como en el manejo de los equipos de visionado o audición de los documentos. El investigador tiene la posibilidad de capturar las imágenes y exportarlas mediante documentos de tratamiento de texto. La Inateca completa su trabajo organizando cursos y seminarios orientados a la utilización de las fuentes documentales de radio y televisión.

\subsection{El acceso para los profesionales y empresas del sector audiovisual}

En el marco de su cometido y competencias es habitual que la Direcciones Comerciales de las empresas de televisión, vendan programas y otro tipo de documentos que forman parte de su archivo y son, en muchas ocasiones, activos muy importantes de su cartera comercial; hoy en dia, es habitual que utilicen también su página web para la comercialización de sus fondos documentales. En el caso de TVE, por ejemplo, la página web Rtve Comercial, hace referencia a "más de un millón de horas de archivo audiovisual a la venta ". Otras cadenas de televisión, como por ejemplo BBC, tienen accesible el línea su catálogo de programas a la venta ${ }^{15}$.

\footnotetext{
${ }^{15}$ Departamentos comerciales de RTVE:http://comercial.rtve.es/html/productos/archivo/archivo.html BBC: http://www.bbcmotiongallery.com/gallery/home/archives.do
} 
La gestión de los derechos influye de manera directa en la producción de las obras audiovisuales por parte de estas empresas, en las negociaciones que se realizan para la compra de imágenes y en la venta de las mismas a terceros.

\subsection{El acceso para el sector académico (con fines educativos)}

El sector educativo emplea desde hace tiempo recursos audiovisuales en las aulas como parte de su estrategia didáctica. Actualmente, los niños y adolescentes no necesitan apenas formación en cuanto a las competencias de lectura de documentos audiovisuales y tampoco necesitan habitualmente alfabetización informática o tecnológica en general. Evidentemente, en este tercer supuesto, no se plantea en ningún caso el acceso físico del sector académico en pleno, profesores y alumnos, a los archivos de televisión, cosa impensable ya que, como se ha explicado, son archivos eminentemente empresariales, no archivos o bibliotecas públicos, en los que los profesionales trabajan a diario al ritmo de la redacción y la producción del medio de comunicación; lo que se plantea es la elaboración de productos documentales con carácter educativo a partir de los fondos de los archivos de las televisiones. El video es un apoyo didáctico esencial en la enseñanza y son muy habituales las lecciones en video (gran parte de los programas didácticos que hay actualmente en el mercado incluso en internet, son cursos a base de video-lecciones).

Las empresas de televisión establecen colaboraciones con proyectos audiovisuales que se desarrollan en el ámbito de la educación, lo que puede ser también una actividad de negocio rentable desde el punto de vista empresarial. No se trata sólo de vender los programas de las cadenas de televisión que tienen potencialmente carácter educativo sino también de realizar y producir materiales audiovisuales, utilizando los documentos de sus archivos. Citamos algunos ejemplos al respecto:

- El programa "La aventura del Saber" es el resultado de la colaboración de la UNED y RTVE, desde el año 1993, y en todo este tiempo se han difundido cientos de horas de divulgación científica en el marco de una televisión pública educativa. Asimismo todos los programas emitidos pasan a formar parte del repositorio de RTVE A la carta, en la página web de TVE, http://www.rtve.es/alacarta/videos/la-aventura-del-saber/ desde donde se pueden volver a visionar y descargar en cualquier momento.

- La página web EDU3, http://www.edu3.cat, patrocinada por la Generalitat de Catalunya, contiene documentos audiovisuales de carácter educativo, bastantes de ellos del archivo de TV3. Canal Sur participa también un proyecto educativo audiovisual, en el que se incluyen fondos documentales del archivo de esta televisión. Nos referimos a la página web "EducAcción.tv", http://educaccion.tv/. 
- En el continente americano, lejanos geográficamente, pero cercanos a nuestras coordenadas por cuestiones históricas, culturales y lingüísticas, podemos analizar el funcionamiento al respecto de La Asociación de las Televisiones Educativas y Culturales Iberoamericanas (ATEI) ${ }^{16}$ que es uno de los proyectos -aprobado en las Cumbres de Jefes de Estado y de Gobierno- que muestra mayor nivel de desarrollo en sus más de 10 años de existencia. La importancia de este proyecto de cooperación internacional que, a partir de su servicio de TV educativa para más de 200 instituciones de 23 países, ha tenido como consecuencia la formación del banco audiovisual de temas educativos más grande del mundo, en el que colaboran algunas de las cadenas de televisión de los países miembros.

\subsection{El acceso para usuarios y público en general a través de internet}

Desde hace ya algunos años, se pueden ver los programas de televisión de las diferentes cadenas a través de internet. Sin embargo, no es tan habitual que a través de su página web las televisiones posibiliten el acceso a sus fondos documentales audiovisuales, el acceso a sus archivos.

Hay diversos factores que han favorecido los procesos para poner los contenidos de los archivos audiovisuales a disposición de los usuarios en internet, entre ellos, el interés de los propios ciudadanos, la demanda de contenidos audiovisuales en los mercados relacionados con la comunicación, la existencia de fondos documentales audiovisuales de televisión cada vez más importantes y la evolución de la tecnología para el almacenamiento y la transmisión de este tipo de documentos a través de la red.

No obstante, hay también algunos factores que dificultan esta posibilidad y que deben tenerse en cuenta: el derecho a la propiedad intelectual, el derecho a la propia imagen, o los derechos inherentes a la producción y comercialización de las producciones audiovisuales...Internet y el acceso electrónico a estos fondos documentales no satisfacen todas las necesidades y siempre perdurarán determinadas limitaciones físicas, técnicas y financieras. El acceso a los fondos de los archivos de televisión a través de los sitios web de estas empresas, resulta también limitado ya que, como es obvio, no está accesible la totalidad del fondo documental que se conserva. Las televisiones efectúan una selección de documentos aplicando criterios diversos (programas emitidos, producción propia, documentos al hilo de la actualidad informativa, derechos, etc.).

"La nueva tecnología y la mayor diversidad de modos de distribución y acceso han generado nuevas oportunidades comerciales para las imágenes y sonidos antiguos. El derecho público al acceso gratuito cede terreno ante la ampliación y la mayor comple-

\footnotetext{
${ }^{16}$ Programa de Cooperación de las Cumbres Iberoamericanas de Jefes de Estado y de Gobierno, cuya misión es contribuir al desarrollo de la educación, la ciencia y la cultura en Iberoamérica, mediante la utilización de la televisión y demás tecnologías de la información y comunicación
} 
jidad de los imperativos jurídicos, a la vez que los gobiernos prorrogan la vigencia de los derechos de autor como consecuencia de la presión del mundo empresarial" ${ }^{, 17}$.

Las principales filmotecas del mundo, importantes agencias de noticias internacionales, algunas cadenas de televisión y algunos organismos públicos que conservan los Archivos Audiovisuales de sus países, disponen en su página web de secciones en las que se puede buscar, recuperar e incluso comprar la documentación audiovisual con informaciones sobre personas, lugares, temas, acontecimientos históricos, etc. que existe en sus archivos.

La Orden del Ministerio de Cultura de 30 de marzo de $2007^{18}$, referida a la constitución de la Comisión Española sobre digitalización y accesibilidad en línea y la conservación digital, hace referencia a la digitalización y "accesibilidad en línea" del material cultural en el que se incluye específicamente el "material audiovisual".

El empleo de las nuevas tecnologías debería permitir el acceso en línea a los documentos de los archivos audiovisuales de las televisiones y del resto de las instituciones que los custodian. La posibilidad de consultar las bases de datos, y acceder a los documentos de los archivos de televisión en línea, a través de las páginas web de estas empresas, puede solventar las necesidades de usuarios en general y de los investigadores en particular, ya que la distancia física en muchas ocasiones es un obstáculo insalvable para su trabajo. Insistimos en la idea de que el posicionamiento de los fondos del archivo de las televisiones en la red debe hacerse de manera absolutamente coherente a la legislación vigente en cada país sobre derechos de autor y demás derechos conexos.

Este servicio de las televisiones a través de internet no tiene por qué ser gratuito en todos los casos, sino que debería depender de diversos factores, como por ejemplo, el uso que se haga del mismo, es decir, son perfectamente compatibles las tarifas para uso comercial, con tarifas reducidas para reutilizar el material con fines culturales, sociales, etc. incluso la gratuidad en el caso de los investigadores, organizaciones sin ánimo de lucro, etc. La documentación audiovisual es muy costosa de gestionar y preservar por lo que las empresas de televisión pueden recuperar y rentabilizar una parte de sus inversiones cobrando algunos de estos usos. Citaremos brevemente a continuación tres ejemplos en los que las páginas web de las televisiones posibilitan el acceso a sus archivos, de una u otra manera:

- Televisión Española S.A. (TVE)

Desde hace tiempo, la web de RTVE puso al alcance de los internautas, de manera gratuita, algunos documentos del archivo histórico de TVE. El " Archivo" en la

\footnotetext{
${ }^{17}$ Edmondson, R. Op. Cit. p.5

${ }^{18}$ ORDEN CUL/1014/2007, de 30 de marzo, por la que se constituye la Comisión Española sobre la digitalización y la accesibilidad en línea del material cultural y la conservación digital, BOE de 18 de abril de 2007, nº 93, págs.16995-16996.
} 
página web de RTVE, está estructurado en "secciones" (música, cine, humor, etc.), algunas de las cuales han ido surgiendo por la propia dinámica de funcionamiento de la página y otras por las peticiones reiteradas de los usuarios para que un tipo de programas o documentos audiovisuales del archivo pudieran ser accesibles, a través del apartado "Tu opinión".

- Televisó de Catalunya (TV3)

También el archivo de TV3 está presente en su página web, aunque no aparece muy visible en la página principal (abajo al final de la página, en letra pequeña...). Contiene videos desde el año 2000, de nueva producción y procedentes del fondo antiguo. No hay posibilidades de buscar libremente por parte del usuario, sino que existen una serie de filtros cronológicos, temáticos y por forma periodística (entrevistas, documentales, reportajes, etc.). En la sección TV3a la carta, también se puede acceder a algunos programas conservados en el archivo de la cadena.

- Canal Sur

El archivo de Canal Sur Televisión trabaja en la actualidad en una página propia dentro de la web corporativa, que esperan pueda visitarse en otoño de este año. De momento, el archivo está presente a través de la opción "Emisiones a la carta". En marzo de 2013, Canal Sur ha presentado oficialmente el proyecto "Memoranda", concebido como medio de difusión del patrimonio audiovisual de los andaluces. El Archivo ahora abre sus puertas en colaboración con la Dirección de Medios Interactivos de RTVA, y posicionan en Memoranda las imágenes "que deben recordarse" o que forman parte de la memoria de los espectadores, la auténtica memoria audiovisual de Andalucía desde 1989. El blog Memoranda, gestionado por el Departamento de Archivo Documentación y Biblioteca de Canal Sur, está accesible a través de la página web de la RTVA y a través de Youtube.

- Proyecto VideoActive ${ }^{19}$

En el seno de la Unión Europea surge también el proyecto "VideoActive", financiado por el programa eContentPlus de la Comisión Europea. El proyecto se iniciaba en septiembre de 2006, en principio con una duración de 36 meses. Algunos de los documentos que se pueden consultar ya en red como resultado de este proyecto, pertenecen a los archivos de varias televisiones públicas europeas, entre ellas la TVC (Televisó de Catalunya). Sin embargo, el proyecto VideoActive se ha visto frenado en gran parte por los múltiples problemas de índole jurídica derivados de la existencia de diferentes legislaciones sobre propiedad intelectual en cada país europeo o por la falta

\footnotetext{
${ }^{19}$ Proyecto de colaboración europeo que pretende la aproximación temática tanto a la historia de Europa a través de la televisión como a la historia de la televisión europea; el proyecto tiene entre sus metas establecer puentes de colaboración con el mundo académico http://www.videoactive.eu.
} 
de normativa común sobre las denominadas "obras huérfanas" (obras cuyo titular se desconoce o es incierto).

- Proyecto EUScreen ${ }^{20}$

En la actualidad ha tomado el relevo el proyecto EUscreen que tiene como objetivo promover el uso de los contenidos de televisión para explorar la rica y diversa historia cultural de Europa. El portal web de este proyecto proporcionará el acceso a más de 30.000 ítems de contenidos audiovisuales de diversas televisiones europeas desarrollando sistemas de interoperabilidad con las colecciones albergadas en Europeana $^{21}$, de manera que se puedan satisfacer las necesidades de los usuarios en el ámbito de la cultura, la educación y el público en general. El consorcio de este proyecto lo forman 28 socios y 9 entidades, pertenecientes a 20 países; el archivo audiovisual de TV3 es el único miembro participante en el proyecto en lo que a las televisiones del estado español se refiere.

\section{CONCLUSIONES}

La televisión sigue siendo desde su creación el principal canal de comunicación social; su producción anual rebasa con mucho la producción cinematográfica. La mayoría de las televisiones que acumulan ya largos años de trayectoria, sobre todo las pertenecientes al sector público, conservan documentos audiovisuales prácticamente desde sus inicios, al menos los documentos más importantes para la historia política, social y cultural de sus países.

La Recomendación de Belgrado ${ }^{22}$, en sus "Principios Generales", punto 6, dice que «se debería facilitar el más amplio acceso posible a las obras y fuentes de información que representan las imágenes en movimiento adquiridas, salvaguardadas y conservadas por instituciones públicas o privadas de carácter no lucrativo. La utilización de esas imágenes en movimiento no debería perjudicar los derechos legítimos ni los intereses de quienes intervienen en su producción y explotación, según lo estipulado en la Convención universal sobre derecho de autor, el Convenio de Berna, y en la legislación nacional». También el acceso universal al patrimonio documental era uno de los tres objetivos básicos del Programa Memoria del Mundo.

En la actualidad, no se cuestiona la gestión ni la preservación de los archivos audiovisuales de televisión en España, tanto públicos como privados; se cuestiona el acceso a los mismos por parte de los ciudadanos, especialmente a los de las televisio-

\footnotetext{
${ }^{20} \mathrm{http}: / /$ www.euscreen.eu/about.html

${ }^{21}$ Biblioteca digital europea http://www.europeana.eu/

${ }^{22} \mathrm{http} / /$ portal.unesco.org/es/ev.php-url_id=45692\&url_do=do_topic\&url_section=201.html
} 
nes de titularidad pública, de la misma manera que se accede a los archivos públicos que albergan otro tipo de documentos.

Conservar los documentos no es por sí mismo un fin para los profesionales de los archivos de las televisiones. Se conservan con el claro propósito de que puedan ser reutilizados, de que la información que contienen se transmita a través del tiempo y el espacio y de que los usuarios potenciales puedan acceder a ella.

"Nuestra intención no es conservar porque sí, sino para facilitar el acceso a estos tesoros documentales", explicaba el responsable del programa Memoria del Mundo, Abdelaziz $\mathrm{Abid}^{23}$. Hacerlos públicos ayuda a atraer recursos para su conservación.

La posibilidad de acceso a los archivos audiovisuales y también a los de las televisiones, guarda una relación directa con la existencia de políticas públicas orientadas a la protección y preservación del patrimonio audiovisual y sobre todo, tiene relación directa con el grado de conciencia que las sociedades tienen sobre el valor cultural y social de este acervo. La falta de marcos legales específicos al respecto hace que la conservación y preservación de estos archivos y por supuesto su accesibilidad, queden al libre criterio y voluntad de cada empresa, institución o persona que los posee.

Según El Programa General de Información y UNISIST, en un mundo en el que la titularidad y la explotación de los derechos de autor revisten una dimensión comercial importantísima, el archivero audiovisual debe hallar el equilibrio entre estos derechos legítimos y el derecho universal de acceso a la memoria pública, del cual forma parte el derecho a que se garantice la supervivencia de una obra publicada sin que los derechos de autor vengan a entorpecer la labor. Fomenta este valor el concepto de depósito legal, habitual en el caso de los libros y el material impreso que adquieren las bibliotecas y en la actualidad paulatinamente ampliado a la esfera de los documentos audiovisuales. Los archiveros audiovisuales operan en entornos comerciales y no comerciales que no se excluyen mutuamente; es frecuente que tengan que oponer los juicios sobre el valor cultural a las exigencias de la explotación comercial.

La variedad de soportes y la inestabilidad de los mismos, hacen a los documentos audiovisuales muy susceptibles de deterioro y les convierten en uno de los fondos documentales más difíciles y más costosos de conservar. A la alteración de los soportes físicos se une la desaparición de los equipos (moviolas, magnetoscopios, etc.) que permiten su lectura y reproducción. Puesto que la vida física de cada tipo de documento y los recursos de cada archivo son distintos, lo normal es que exista en cada archivo de televisión un plan de preservación ad hoc y una estrategia de conservación que incluye la digitalización de los fondos documentales, lo que posibilita más aún el acceso de los usuarios a los documentos.

La contribución de los archivos audiovisuales de televisión a la creación y mantenimiento de "la memoria colectiva" está fuera de toda duda en estos momentos. La

\footnotetext{
23 "El patrimonio documental en la era digital: entrevista con Abdelaziz Abid" http://unesdoc.unesco.org/images/0018/001894/189454s.pdf
} 
televisión produce gran cantidad de información diaria, de temática diferente, muy relacionada con la realidad social, política y cultural de cada momento y de cada sociedad. Además de su valor económico, las producciones de televisión son una ventana abierta al pasado de nuestra historia y nuestras sociedades que nos permite revivir, reflexionar y analizar los hechos con la perspectiva que sólo da el tiempo transcurrido.

La máxima de que "los archivos que no se utilizan no son útiles", no es aplicable en el caso de los archivos de televisión ya que los propios organismos productores y propietarios reutilizan sus fondos a diario; la accesibilidad a estos archivos hay que plantearla y estudiarla desde otro punto de vista, desde la necesidad que el estudio de la sociedad, la historia, la política, los movimientos artísticos, etc. de los siglos XX y XXI, necesitan estos documentos audiovisuales como fuentes documentales básicas para ser estudiados y analizados.

Los documentalistas audiovisuales deben contribuir a salvaguardar la información contenida en estos documentos, en cuanto a Memoria de la Humanidad, y promover la investigación basada en este tipo de fuentes documentales. Igualmente, los responsables de los archivos audiovisuales, incluso los de las empresas de radiodifusión, cuya primera misión debe ser gestionar estos fondos documentales de manera que faciliten y garanticen la elaboración de la producción diaria de las cadenas de televisión, no deberían olvidar esta función de guardianes del patrimonio audiovisual de la humanidad, especialmente cuando se trata de cadenas de televisión de titularidad pública.

Los gobiernos y las administraciones deberían asumir la responsabilidad de la conservación de este patrimonio documental, incluyendo para ello las emisiones de televisión en el depósito legal y creando los mecanismos adecuados para la elaboración de leyes, políticas y protocolos, que posibiliten la preservación, digitalización y acceso a los documentos audiovisuales de las televisiones, rebasando así el marco de los ámbitos empresariales, profesionales especializados y académicos, para convertirlo en "una cuestión de interés público".

Insistimos en que la receta para lograr una adecuada accesibilidad a los archivos audiovisuales debe combinar varios elementos: voluntad política, movilización de la comunidad intelectual y de los ciudadanos y una reglamentación acorde con los intereses de todos (productores, difusores, etc.). Además, no es suficiente una legislación apropiada sino también que los gobiernos garanticen las estructuras, los medios técnicos y humanos y el dinero necesarios para que esta posibilidad quede asegurada.

Aunque existan limitaciones de orden práctico a la conservación y el acceso, no debería haber limitaciones artificiales, principio que concuerda con la Declaración Universal de Derechos Humanos de las Naciones Unidas (1948) y su Pacto Internacional de Derechos Civiles y Políticos (1966). Todo individuo tiene derecho a una identidad y, por consiguiente, tiene derecho de tener acceso a su patrimonio documental, comprendido el patrimonio audiovisual, lo que comprende saber que éste existe y dónde se encuentra. 
El nivel de democracia de una sociedad se mide también por la calidad y gestión de sus archivos y por el acceso de los ciudadanos a los documentos que conservan. Además, la comunicación, la información y el saber, son pilares importantes del desarrollo sostenible.

El empleo de las nuevas tecnologías facilita el acceso a los documentos de los archivos audiovisuales de las televisiones y del resto de las instituciones que los custodian. Es posible situar a disposición de los ciudadanos a través de internet bases de datos y documentos, de manera que se pueda dar respuesta a su demanda de información, cumpliendo con la legislación vigente en cada país sobre derechos de autor y demás derechos colaterales. De nuestra decisión y trabajo al respecto en la actualidad y en el futuro inmediato depende el objetivo principal: "PRESERVAR Y DIFUNDIR LA MEMORIA AUDIOVISUAL COLECTIVA"

Los documentos que gestionan y conservan las cadenas de televisión, forman parte del patrimonio histórico y cultural de nuestras sociedades y por tanto deben seguir preservándose. El debate ahora es la accesibilidad a estos archivos, plantear lo que se debería hacer, lo que se puede hacer y comprobar lo que se va a hacer realmente. Si los archivos de televisión siguen en su condición de ser inaccesibles, estamos condenados a perder "una parte muy importante de nuestra memoria colectiva". Muchos documentos duermen en los archivos de las televisiones esperando que alguien los despierte y revele sus contenidos, las realidades que contienen. La posibilidad de investigar en estas fuentes documentales "nos permitirá prevenir la amnesia colectiva" de la que nos alertaba Irina Bukova ${ }^{24}$, Directora General de UNESCO.

\footnotetext{
${ }^{24} \mathrm{http}$ //unesdoc.unesco.org/images/0021/002132/213287s.pdf
} 